in vivo 35 : $969-975(2021)$

doi:10.21873/invivo.12339

\title{
Cytotoxic T-lymphocyte Antigen-4 (CTLA-4) Gene Polymorphism (rs3087243) Is Related to Risk and Survival in Patients With Colorectal Cancer
}

\author{
SONG VAN NGUYEN ${ }^{1}$, LEVAR SHAMOUN ${ }^{2,3}$, KALLE LANDERHOLM ${ }^{4}$, \\ ROLAND E. ANDERSSON ${ }^{4}$, DICK WAGSATER ${ }^{3}$ and JAN DIMBERG ${ }^{5}$ \\ ${ }^{1}$ Department of Medical Laboratory, Danang University of Medical Technology and Pharmacy, Danang, Vietnam; \\ ${ }^{2}$ Department of Laboratory Medicine and Pathology, Region Jönköping County, Jönköping, Sweden; \\ ${ }^{3}$ Department of Medical Cell Biology, Uppsala University, Uppsala, Sweden; \\ ${ }^{4}$ Department of Surgery, Region Jönköping County, Jönköping, Sweden; \\ Department of Biomedical and Clinical Science, Linköping University, Linköping, Sweden; \\ ${ }^{5}$ Department of Natural Science and Biomedicine, School of Health and Welfare, \\ Jönköping University, Jönköping, Sweden
}

\begin{abstract}
Background/Aim: Cytotoxic T-lymphocyte antigen4 (CTLA-4), transiently expressed on $T$ cells, plays a pivotal role in the negative feedback regulation of $T$-cell activation and proliferation. The aim of the present study was to examine the influence of CTLA-4 gene polymorphism rs3087243 on CRC susceptibility and long-term survival in Swedish patients with CRC. Patients and Methods: Genotypes of 491 patients and 433 healthy controls were determined, using TaqMan single nucleotide polymorphism (SNP) assays based on polymerase chain reaction. Results: Patients carrying allele A were found to be at a higher risk of CRC and this allele was found to be more common in patients with disseminated disease compared to localized disease in the right colon. Kaplan-Meier analysis of cancer-specific survival showed that carriers of allele A had the highest risk of CRC-related death. Conclusion: The SNP rs3087243 of the CTLA-4 gene was associated with CRC risk and, therefore, it could be a prognostic marker for Swedish patients with CRC.
\end{abstract}

Colorectal cancer (CRC) is one of the most common and deadly cancers worldwide (1). The etiology of CRC is not completely known. Various genetic pathways affecting CRC induction and progression have been described (2). The link

This article is freely accessible online.

Correspondence to: Dr. Jan Dimberg, Natural Science and Biomedicine, School of Health and Welfare, Jönköping University, Jönköping, Sweden. Tel: +46 705913908, e-mail: jan.dimberg@ju.se

Key Words: CTLA-4, SNP, colorectal cancer. between inflammation and CRC is well-established (3-5). Inflammatory factors such as interleukins and chemokines are produced by tumor cells or by cells in the tumor microenvironment such as lymphocytes (5-7). A dominant anti-tumor response is cell mediated and involves $\mathrm{T}$ lymphocytes and natural killer (NK) cells $(4,8)$.

Cytotoxic T-lymphocyte antigen-4 (CTLA-4), also known as CD152, is transiently expressed on $\mathrm{T}$ cells and plays a pivotal role in the negative feedback regulation of T-cell activation and proliferation (9). The CTLA-4 receptor also limits CD28 receptor-mediated signaling that activates $\mathrm{T}$ cells. Checkpoint proteins, such as B7-1 (CD80) and B7-2 (CD86) on antigen presenting cells (APC) and CTLA-4 receptor on $\mathrm{T}$ cells, contribute to the control of the immune response. The binding of B7-1 and B7-2 to CTLA-4 keeps T cells in an inactive state and thereby, the antitumor effect is lost. CTLA-4 protein exists in two forms, a membrane bound and a soluble isoform (sCTLA-4) with immunoregulatory properties $(10,11)$. Treatment with CTLA-4 blocking antibodies has been shown to result in increased activation of $\mathrm{T}$ cells and has led to immunotherapies for melanoma and non-small cell lung cancer $(10,12)$.

In general, CRC staging is based on the tumor-nodesmetastasis (TNM) system according to The American Joint Committee on Cancer (AJCC) classification system (13). CRC patients are identified based on pathological and clinical parameters and some of them are considered weak prognostic markers $(14,15)$. The identification of molecular biomarkers is important to select CRC patients for personalized therapy and improve patient prognosis $(16,17)$.

Genetic variations in inflammatory genes $(18,19)$ and other genes (20) have been suggested to play a role in CRC 
Table I. Genotypic and allelic distributions in \% (n) of the CTLA4 gene polymorphism (rs 3087243) in CRC patients and controls.

\begin{tabular}{lccccc}
\hline Genotype & $\begin{array}{c}\text { CRC } \\
(\mathrm{n}=491)\end{array}$ & $\begin{array}{c}\text { Control } \\
(\mathrm{n}=433)\end{array}$ & Allele & $\begin{array}{c}\mathrm{CRC} \\
(\mathrm{n}=982 \\
\text { alleles })\end{array}$ & $\begin{array}{c}\text { Controls } \\
(\mathrm{n}=866 \\
\text { alleles })\end{array}$ \\
\hline $\mathrm{G} / \mathrm{G}$ & $35.0(172)$ & $41.6(180)$ & & & \\
$\mathrm{G} / \mathrm{A}$ & $47.5(233)$ & $46.4(201)$ & $\mathrm{G}$ & $58.8(577)$ & $64.8(561)$ \\
$\mathrm{A} / \mathrm{A}$ & $17.5(86)$ & $12.0(52)$ & $\mathrm{A}$ & $41.2(405)$ & $35.2(305)$ \\
G/A+A/A & $65.0(319)$ & $58.4(253)$ & & & \\
\hline
\end{tabular}

CRC patients $v s$. healthy controls: genotypes overall $p=0.026$ and alleles, $p=0.008 ; \mathrm{G} / \mathrm{G} v s . \mathrm{G} / \mathrm{A}+\mathrm{A} / \mathrm{A}, p=0.041$.

susceptibility and in the survival of CRC patients. The CTLA-4 single nucleotide polymorphism (SNP) rs3087243, also called CT60, is located in the 3'-untranslated region (10) and associated with susceptibility to autoimmune diseases $(11,21)$. Various studies have shown an association between this SNP and cancer diseases such as breast (22), liver (23), renal (24) and skin cancer (25), but only a few reports of weak association have been published regarding CRC (26). The aim of the present study was to examine the influence of CTLA-4 gene polymorphism rs3087243 on CRC susceptibility and the link with various clinical features such as stage, differentiation and localization of the tumor and long-term survival in Swedish patients with CRC.

\section{Patients and Methods}

Patients and controls. This study comprised blood samples from 491 consecutive patients (266 males and 225 females) with a mean age of 71 years (range=25-94 years) who underwent surgical resection for primary colorectal adenocarcinoma at the Department of Surgery, Ryhov County Hospital, Jönköping, Sweden between 1996 and 2016. Blood samples were collected at the start of surgery and patient data were prospectively recorded in a database. Followup for the estimation of cancer specific survival ended on the date of death or on July 16, 2020.

According to the primary site of the tumor, this study included 229 patients with rectum cancer and 262 patients with colon cancer. In accordance with Liang et al. (27) the patients were divided into those with cancer localized in the right colon (cecum, ascending colon, hepatic flexure, transverse colon) or left colon (splenic flexure, descending colon, sigmoid colon). A total of 154 and 108 patients had right and left colon cancers, respectively. The tumors were classified according to AJCC (13): stage I in 83, stage II in 180 , stage III in 160 and stage IV in 68. The degree of differentiation was divided into high/medium with 376 cases and poor with 114 cases.

Healthy blood donors $(n=433)$ at County Hospital Ryhov were collected as the control population at the time of the blood donation. The control population with no known CRC history was from the
Table II. Genotype numbers of the CTLA4 gene polymorphism (rs3087243) regarding tumor location and disease stage in patients (n=491) with $C R C$.

\begin{tabular}{|c|c|c|c|c|c|}
\hline \multirow[t]{2}{*}{ Variables } & \multirow[t]{2}{*}{ Cases (n) } & \multicolumn{3}{|c|}{ Genotype } & \multirow[t]{2}{*}{$p$-Value } \\
\hline & & $\mathrm{G} / \mathrm{G}$ & $\mathrm{G} / \mathrm{A}$ & $\mathrm{A} / \mathrm{A}$ & \\
\hline Rectum & 229 & 83 & 104 & 42 & \\
\hline Colon & 262 & 89 & 129 & 44 & 0.697 \\
\hline Right colon & 154 & 53 & 68 & 33 & \\
\hline Left colon & 108 & 36 & 61 & 11 & 0.034 \\
\hline \multicolumn{6}{|l|}{ Rectum } \\
\hline \multicolumn{6}{|l|}{ Stage } \\
\hline $\mathrm{I}+\mathrm{II}$ & 122 & 46 & 56 & 20 & \\
\hline III+IV & 107 & 37 & 48 & 22 & 0.701 \\
\hline \multicolumn{6}{|l|}{ Right colon } \\
\hline \multicolumn{6}{|l|}{ Stage } \\
\hline $\mathrm{I}+\mathrm{II}$ & 88 & 37 & 38 & 13 & \\
\hline III+IV & 66 & 16 & 30 & 20 & 0.021 \\
\hline \multicolumn{6}{|l|}{ Left colon } \\
\hline \multicolumn{6}{|l|}{ Stage } \\
\hline $\mathrm{I}+\mathrm{II}$ & 53 & 22 & 24 & 7 & \\
\hline III+IV & 55 & 14 & 37 & 4 & 0.070 \\
\hline
\end{tabular}

same geographical region (southeastern Sweden) as the CRC patients and comprised 229 males and 204 females, with a mean age of 58 years (range=33-68 years). All blood samples were centrifuged to separate plasma and blood cells and then stored frozen at $-70^{\circ} \mathrm{C}$ until analysis.

The investigation was approved by the Regional Ethical Review Board in Linköping, Linköping, Sweden (Dnr. 2013/271-31) and informed consent was obtained from each of the participants.

Genotyping of CTLA-4 gene polymorphism. DNA was isolated from all blood samples using the QiaAmp DNA Blood Kit (Qiagen, Hilden, Germany). The TaqMan SNP genotype assays were used for the analysis of the CTLA-4 rs3087243 (ID C-3296043) genotypes (Applied Biosystems, Foster City, CA, USA). Ten ng DNA was mixed with TaqMan Genotyping Master Mix (Applied Biosystems) and was analyzed using the 7500 Fast Real-Time Polymerase Chain Reaction (PCR) System (Applied Biosystems). The PCR conditions were an initial cycle at $50^{\circ} \mathrm{C}$ for 2 min followed by one cycle at $95^{\circ} \mathrm{C}$ for $10 \mathrm{~min}$ and finally 40 cycles at $95^{\circ} \mathrm{C}$ for $15 \mathrm{~s}$ and at $60^{\circ} \mathrm{C}$ for $1 \mathrm{~min}$. The allelic discrimination application ABI PRISM 7500 SDS software version 1.3.1 (Applied Biosystems) was used to characterize the genotypes.

Statistical analysis. The differences in the genotypes of the CTLA4 gene polymorphism between CRC patients and the control subjects and the subgroups of CRC patients according to clinical parameters were analyzed using the Chi-squared test. The HardyWeinberg equilibrium was tested for the genotypes. Survival analysis was analyzed by the Kaplan-Meier method with log-rank test and Cox's regression. Statistical analysis was performed using Stata Statistical Software Release 15 (Stata Corp. College Station, TX, USA) and SPSS software for Windows, version 14.0 for (SPSS Inc., Chicago, IL, USA). Differences were considered to be statistically significant at $p<0.05$. 


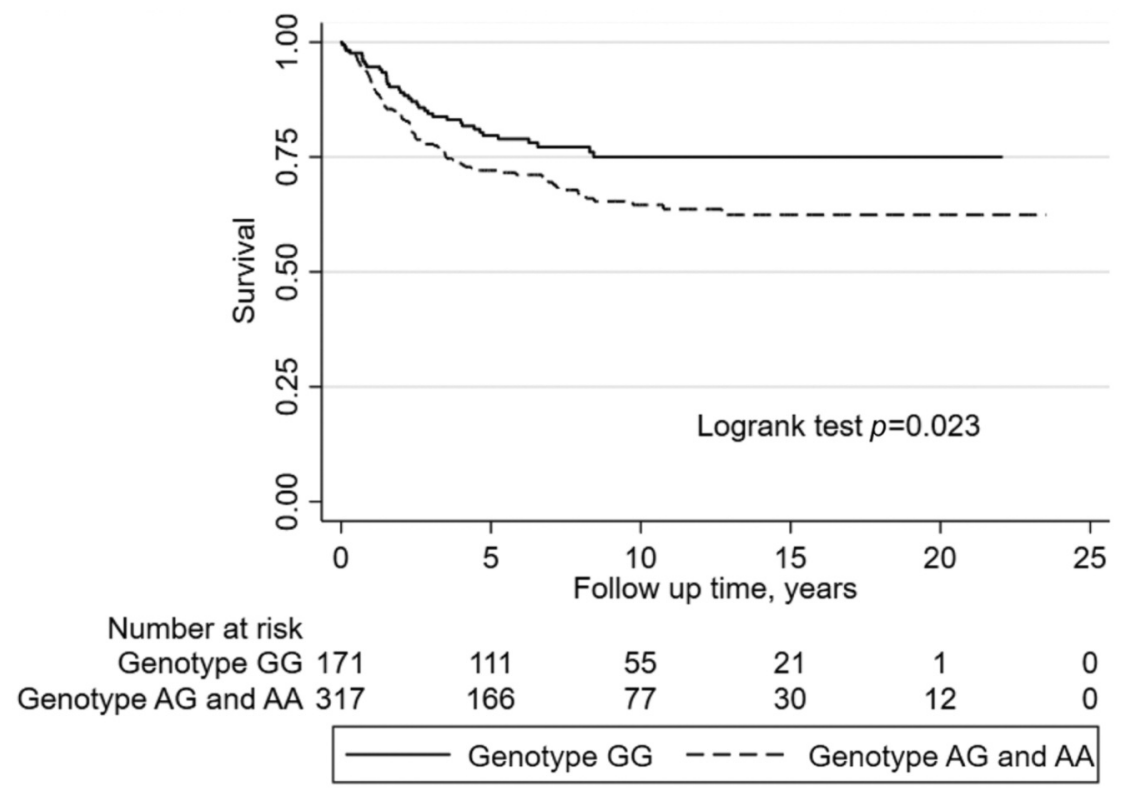

Figure 1. Kaplan-Meier plot comparing cancer-specific survival among CRC patients regarding to genotypes of rs3087243 SNP of CTLA-4 gene.

\section{Results}

Association of CTLA-4 gene polymorphism and the risk of $C R C$. Significant differences in the genotype and allele distributions were observed between the patients and the healthy control group for CTLA-4 rs3087243 (Table I). Moreover, the prevalence of the $\mathrm{G} / \mathrm{G}$ genotype was $35.0 \%$ and that of $\mathrm{G} / \mathrm{A}+\mathrm{A} / \mathrm{A}$ was $65.0 \%$ among patients, whilst $41.6 \%$ and $58.4 \%$ existed in the healthy control group, respectively. The carriers of the A allele (G/A+A/A) were found to be at increased risk of CRC with an odds ratio (OR) of 1.32 [95\% confidence interval $(\mathrm{CI})=1.01-1.72 ; p=0.041$ ] The patients and the control group were in agreement with the Hardy-Weinberg equilibrium.

Clinicopathological features in relation to CTLA-4 gene polymorphism. Analysis of the association between the genotype variants and the location of the tumor showed no significant difference between the colon and rectum (Table II). Stratification analysis of the association between the CTLA-4 gene polymorphism and the location of the tumor in the colon showed significant difference between the right and left colon (Table II). Furthermore, of the patients with right colon cancer, $78.6 \%(121 / 154)$ carried the G allele, and of those with left colon cancers, $89.8 \%(97 / 108)$ carried the $\mathrm{G}$ allele. Consequently, patients with G-bearing genotypes had tumors located more commonly in the left colon compared to the right colon with an $\mathrm{OR}=2.41(95 \% \mathrm{CI}=1.16-$ $5.00 ; p=0.019)$.
A potential association between genotype variants and disease stage in the rectum, left and right colon was investigated. As shown in Table II, stage I+II (localized disease) and stage III+IV (disseminated disease) differ significantly in the right colon but not in the left colon and rectum regarding the genotype variants. Moreover, the results showed that the rate of the patients with the A allele was $75.8 \%$ (50/66) among those having disseminated disease in the right colon and $57.9 \%$ (51/88) among those with localized disease. This difference was significantly different with an $\mathrm{OR}=2.27 \quad(95 \% \mathrm{CI}=1.12-4.59 ; p=0.023)$. No significant association was found between the genotypes when patients were stratified according to gender, age, or the degree of differentiation (data not shown).

CTLA-4 gene polymorphism and cancer-specific survival. The Kaplan-Meier method revealed that the cancer-specific survival curves were different $(p=0.023)$ between $\mathrm{G} / \mathrm{G}$ and $\mathrm{A} / \mathrm{G}+\mathrm{A} / \mathrm{A}$ for the CTLA-4 SNP (Figure 1). The carriers of the A allele showed the highest risk of CRC death with a hazard ratio (HR) of $1.54 \quad(95 \% \mathrm{CI}=1.06-2.25 ; p=0.025)$. Furthermore, carriers of the A allele exhibited worse cancerspecific survival $(p=0.041)$ in stage III disease with a $\mathrm{HR}=2.02(95 \% \mathrm{CI}=1.01-4.01 ; p=0.046)$ (Figure 2).

\section{Discussion}

Different cytokines and $\mathrm{T}$ lymphocytes contribute to the pathogenesis of CRC $(3-5,8)$. CTLA-4 is expressed on T 


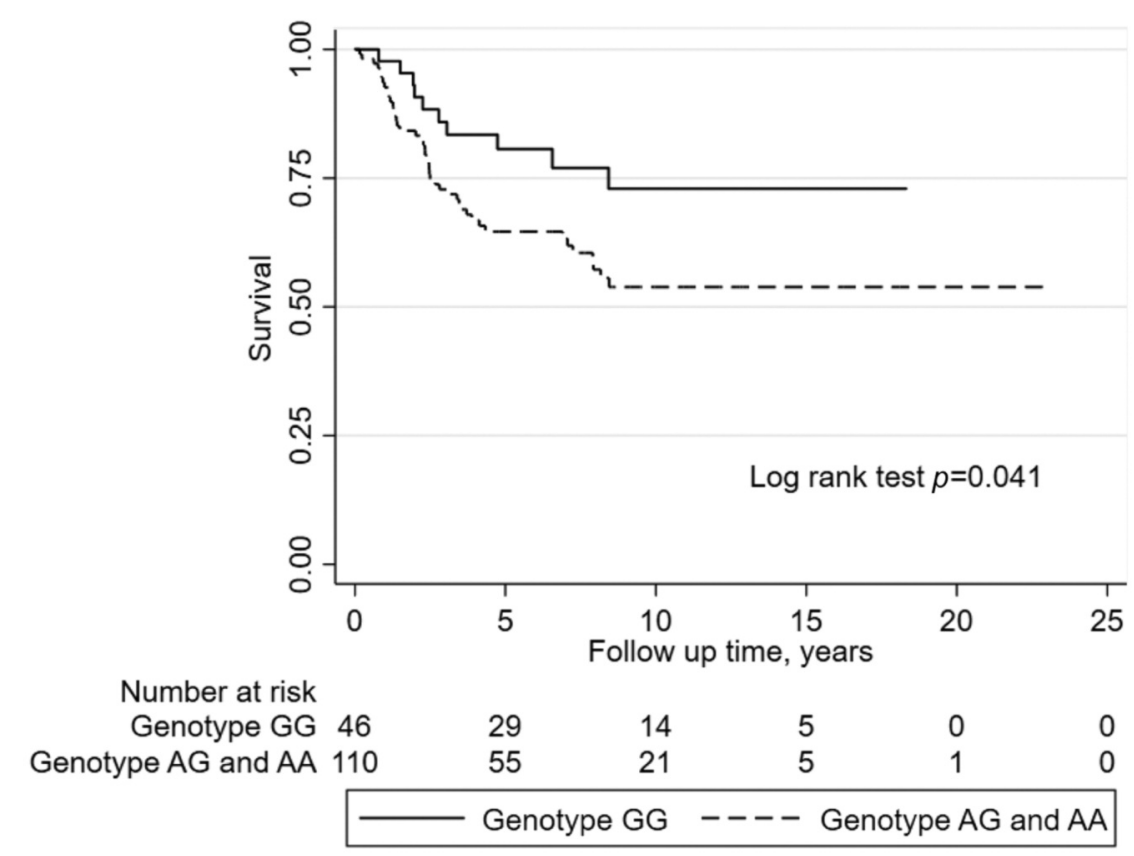

Figure 2. Kaplan-Meier plot comparing cancer-specific survival among CRC patients with stage III regarding to genotypes of rs3087243 SNP of CTLA-4 gene.

cells and is involved in immune tolerance and downregulation of $\mathrm{T}$ cell activation $(9,12)$.

Previous studies have shown that the CTLA-4 gene polymorphism rs3087243 $(\mathrm{G}>\mathrm{A})$ is associated with susceptibility to different cancer diseases (22-25), but only a few reports about CRC have been published (26). Collectively, there is much to suggest that the CTLA-4 gene polymorphism rs3087243 is related to the status of T-cell activation. However, there are limited data about the functional activity of this SNP.

The genetic variants may affect the expression of the CTLA-4 receptor thereby, conferring interindividual differences in the susceptibility to CRC. A previous study has suggested that the A allele of the CTLA-4 gene polymorphism rs3087243 may lead to higher production of sCTLA-4, causing a stronger inhibition of $\mathrm{T}$ cell activation and thereby, a loss of the antitumor effect (24).

$\mathrm{T}$ regulatory (Treg) lymphocytes are one of the subsets of Tlymphocytes, which may impair the immune reaction against cancer $(6,28)$. A recent study showed that healthy individuals carrying the A/A genotype for the CTLA-4 gene polymorphism rs3087243 (G>A) have an increased number of Treg cells in their peripheral blood compared to those with the $\mathrm{G} / \mathrm{G}$ genotype (29). Treg cells are increased in the peripheral blood of patients with various cancers including CRC (28). However, in CRC, the prognostic role of Treg cells remains controversial (30).

This study demonstrated that the CTLA-4 gene polymorphism rs3087243 is associated with susceptibility to
CRC. Specifically, carriers of the A allele among Swedish patients were found to be at increased risk of CRC. This finding is inconsistent with data from Chinese patients with CRC (26), where no significant differences in the genotype frequencies were observed between cancer patients and controls for the CTLA-4 gene polymorphism rs3087243. This might be explained by differences in ethnicity.

The carriers of the A allele of the CTLA-4 rs3087243 polymorphism were found to be associated with the highest risk of CRC death. Furthermore, the carriers of the A allele exhibited poor cancer-specific survival among those with stage III CRC. Together, in our CRC cohort we noted that genotypes with the A allele for CTLA-4 rs3087243 polymorphism predispose to higher risk of CRC, decreased cancer specific survival and advanced stage III disease of patients with CRC. As mentioned above, the genetic variants may affect the expression of the CTLA-4 receptor, but also the number of Treg cells. Interestingly, a study (31) has shown that CRC patients had increased levels of Treg cells in the blood and cancer tissue in comparison to healthy controls and normal colorectal tissue, respectively. Further, analysis showed higher levels of Treg cells in stage III+IV than in stage I+II. However, the role of allele A as a modulating factor of the levels of CTLA-4 and Treg cells in connection with the risk, tumor progression and survival of patients with $\mathrm{CRC}$ requires further investigation.

There are several factors affecting the prognosis of CRC such as communication between CRC cells and their 
microenvironment, genetic variations within inflammatory genes and different activated signaling cascades in later and early stages of $\mathrm{CRC}(2,3,6,32)$. Different pathophysiological mechanisms may be involved in the tumor progression of both the colon and rectum and between the right and left colon (27, 33-35). Right- and left-sided colon cancer differ with respect to histology, pathology, clinical outcomes, and expression of distinguishable genes and this has led to the hypothesis that they are two different disease entities $(27,33,34)$ Thus, tumor location in colon cancer plays a significant role in disease behaviour and is related to different molecular pathways, including different biomarkers $(33,34)$. Moreover, understanding the characteristics of these two different entities seems to be very important regarding the choice of treatment (35).

In this study, we showed no significant difference between the colon and rectum regarding the genotype variants of the CTLA-4 rs3087243 polymorphism. In fact, we showed that the CTLA-4 rs3087243 polymorphism was different between the right and left colon and that patients with G-bearing genotypes had tumors more commonly localized in the left colon compared to the right colon. Moreover, no association between genotype variants and stage I+II (localized disease) and stage III+IV (disseminated disease) in the left colon and rectum was found. However, the results showed that a higher rate of patients bearing the A allele in the genotype was associated with disseminated disease in the right colon compared to localized disease.

Focusing on cancer location within the colon, the genomic make-up of the right and left colon is different from each other. For example, the patients with right sided cancer have more microsatellite high (MSI-high) and BRAF mutated tumors and left sided cancer patients tend to have more chromosomal instability high (CIN) tumors (33-35). Besides the difference in the genomic make-up, the tumors in the right colon seem to have more $\mathrm{T}$ cell infiltrates (36) that could in part be an effect of a genotype bearing allele A and hypothetically may have impacted carcinogenesis, driving toward a more advanced stage (III and IV). There are some studies about autoimmune diseases such as Rheumatoid arthritis (37), which highlight the expression of CTLA-4 in relation to the $\mathrm{G}$ and A alleles in the CTLA-4 rs3087243 polymorphism. In cancer, similar studies are sparse.

Some limitations of our study are worth noting. This study is exploratory. Our data suggest that the CTLA-4 rs3087243 polymorphism is involved in CRC with partially different mechanisms in the rectum and colon. However, detailed functional analysis is required to reveal the mechanisms responsible for the observed associations and clarify the involvement of CTLA-4 rs3087243 polymorphism in colorectal carcinogenesis. The patients and controls were selected from one hospital and may not represent the general population. Therefore, additional studies in larger groups of patients and controls are needed to validate our findings. In addition, it cannot be excluded that this investigated SNP may be linked with other polymorphisms that affect susceptibility to CRC and the prognosis of patients.

In conclusion, the SNP rs3087243 of the CTLA-4 gene is associated with risk and prognosis in Swedish patients with CRC. Further studies with a more diverse population and a higher number of cases will be needed to evaluate whether the involvement of the CTLA-4 rs3087243 polymorphism can be generalized to a broader population.

\section{Conflicts of Interest}

The Authors declare no conflicts of interest in relation to this study.

\section{Authors' Contributions}

Designed the study and prepared the manuscript: SVN, JD and DW. Analyzed data: JD and REA. Performed the laboratory work: LS and SVN. Responsible for patient data and follow-up: KL and REA. All Authors read and approved the final manuscript.

\section{Acknowledgements}

This work was supported by grants from the Medical Research Council of Southeast Sweden and Division of Medical Diagnostics, Region Jönköping County, Sweden.

\section{References}

1 Siegel RL, Miller KD and Jemal A: Cancer statistics, 2018. CA Cancer J Clin 68: 7-30, 2018. PMID: 29313949. DOI: 10.3322/ caac. 21442

2 Al-Sohaily S, Biankin A, Leong R, Kohonen-Corish M and Warusavitarne J: Molecular pathways in colorectal cancer. J Gastroenterol Hepatol 27(9): 1423-1431, 2012. PMID: 22694276. DOI: $10.1111 /$ j.1440-1746.2012.07200.x

3 Klampfer L: Cytokines, inflammation and colon cancer. Curr Cancer Drug Targets 11(4): 451-464, 2011. PMID: 21247378. DOI: $10.2174 / 156800911795538066$

4 Strasser K, Birnleitner H, Beer A, Pils D, Gerner MC, Schmetterer KG, Bachleitner-Hofmann T, Stift A, Bergmann M and Oehler R: Immunological differences between colorectal cancer and normal mucosa uncover a prognostically relevant immune cell profile. Oncoimmunology 8(2): e1537693, 2018. PMID: 30713795. DOI: 10.1080/216402X.1537693

5 Mager LF, Wasmer MH, Rau TT and Krebs P: Cytokine-induced modulation of colorectal cancer. Front Oncol 6: 96, 2016. PMID: 27148488. DOI: 10.3389/fonc.2016.00096

6 Zhou K, Cheng T, Zhan J, Peng X, Zhang Y, Wen J, Chen X and Ying M: Targeting tumor-associated macrophages in the tumor microenvironment. Oncol Lett 20(5): 234, 2020. PMID: 32968456. DOI: $10.3892 / 01.2020 .12097$

7 Poh AR and Ernst M: Targeting macrophages in cancer: From bench to bedside. Front Oncol 8(49), 2018. PMID: 29594035. DOI: $10.3389 /$ fonc .2018 .00049 
8 Pernot S, Terme M, Voron T, Colussi O, Marcheteau E, Tartour $\mathrm{E}$ and Taieb J: Colorectal cancer and immunity: What we know and perspectives. World J Gastroenterol 20(14): 3738-3750, 2014. PMID: 24833840. DOI: $10.3748 /$ wjg.v20.i14.3738

9 Walker LS and Sansom DM: Confusing signals: Recent progress in CTLA-4 biology. Trends Immunol 36(2): 63-70, 2015. PMID: 25582039. DOI: 10.1016/j.it.2014.12.001

10 Zhao Y, Yang W, Huang Y, Cui R, Li X and Li B: Evolving roles for targeting CTLA-4 in cancer immunotherapy. Cell Physiol Biochem 47(2): 721-734, 2018. PMID: 29794465. DOI: $10.1159 / 000490025$

11 Saverino D, Simone R, Bagnasco M and Pesce G: The soluble CTLA-4 receptor and its role in autoimmune diseases: An update. Auto Immun Highlights 1(2): 73-81, 2010. PMID: 26000110. DOI: 10.1007/s13317-010-0011-7

12 Buchbinder EI and Desai A: CTLA-4 and PD-1 pathways: Similarities, differences, and implications of their inhibition. Am J Clin Oncol 39(1): 98-106, 2016. PMID: 26558876. DOI: 10.1097/coc.0000000000000239

13 Amin MB, Greene FL, Edge SB, Compton CC, Gershenwald JE, Brookland RK, Meyer L, Gress DM, Byrd DR and Winchester DP: The eighth edition AJCC cancer staging manual: Continuing to build a bridge from a population-based to a more "personalized" approach to cancer staging. CA Cancer J Clin 67(2): 93-99, 2017. PMID: 28094848. DOI: 10.3322/caac.21388

14 Bockelman C, Engelmann BE, Kaprio T, Hansen TF and Glimelius B: Risk of recurrence in patients with colon cancer stage II and III: A systematic review and meta-analysis of recent literature. Acta Oncol 54(1): 5-16, 2015. PMID: 25430983. DOI: 10.3109/0284186x.2014.975839

15 Enofe N, Morris AD, Liu Y, Liang W, Wu CS, Sullivan PS, Balch GG, Staley CA, Gillespie TW and Shaffer PS: Receipt of adjuvant chemotherapy in stage II colon cancer and overall survival: a national cancer database study. J Surg Res 252: 69-79, 2020. PMID: 32244127. DOI: 10.1016/ j.jss.2020.02.016

16 Yiu AJ and Yiu CY: Biomarkers in colorectal cancer. Anticancer Res 36(3): 1093-1102, 2016. PMID: 26977004.

17 Sagaert X: Prognostic biomarkers in colorectal cancer: Where do we stand? Virchows Arch 464(3): 379-391, 2014. PMID: 24487787. DOI: $10.1007 / \mathrm{s} 00428-013-1532-\mathrm{z}$

18 Ji H, Lu L, Huang J, Liu Y, Zhang B, Tang H, Sun D, Zhag Y, Shang H, Li Y and Lu H: IL1A polymorphisms is a risk factor for colorectal cancer in Chinese Han population: a case control study. BMC Cancer 19(1): 181, 2019. PMID: 30819119. DOI: 10.1186/s12885-019-5395-9

19 Bondurant KL, Lundgreen A, Herrick JS, Kadlubar S, Wolff RK and Slattery ML: Interleukin genes and associations with colon and rectal cancer risk and overall survival. Int J Cancer 132(4): 905-915, 2013. PMID: 22674296. DOI: 10.1002/ijc.27660

20 Wen J, Xu Q and Yuan Y: Single nucleotide polymorphisms and sporadic colorectal cancer susceptibility: A field synopsis and meta-analysis. Cancer Cell Int 18(155), 2018. PMID: 30337837. DOI: 10.1186/s12935-018-0656-2

21 Fang W, Zhang Z, Zhang J, Cai Z, Zeng H, Chen M and Huang J: Association of the CTLA4 gene ct60/rs3087243 singlenucleotide polymorphisms with graves' disease. Biomed Rep 3(5): 691-696, 2015. PMID: 26405547. DOI: 10.3892/br.2015.493

22 Wang L, Li D, Fu Z, Li H, Jiang W and Li D: Association of CTLA-4 gene polymorphisms with sporadic breast cancer in chinese han population. BMC Cancer 7: 173, 2007. PMID: 17825114. DOI: $10.1186 / 1471-2407-7-173$

23 Li J, Wang W, Sun Y and Zhu Y: CTLA-4 polymorphisms and predisposition to digestive system malignancies: A meta-analysis of 31 published studies. World J Surg Oncol 18(1): 55, 2020. PMID: 32178688. DOI: 10.1186/s12957-020-1806-2

24 Cozar JM, Romero JM, Aptsiauri N, Vazquez F, Vilchez JR, Tallada M, Garrido F and Ruiz-Cabello F: High incidence of CTLA-4 AA (CT60) polymorphism in renal cell cancer. Hum Immunol 68(8): 698-704, 2007. PMID: 17678726. DOI: 10.1016/j.humimm.2007.05.002

25 Yan Q, Chen P, Lu A, Zhao P and Gu A: Association between CTLA-4 60G/A and $-1661 \mathrm{~A} / \mathrm{G}$ polymorphisms and the risk of cancers: A meta-analysis. PLoS One 8(12): e83710, 2013. PMID: 24376736. DOI: 10.1371/journal.pone.0083710

26 Zou C, Qiu H, Tang W, Wang Y, Lan B and Chen Y: CTLA4 tagging polymorphisms and risk of colorectal cancer: A casecontrol study involving 2,306 subjects. Onco Targets Ther 11: 4609-4619, 2018. PMID: 30122952. DOI: 10.2147/ott.S173421

27 Liang L, Zeng JH, Qin XG, Chen JQ, Luo DZ and Chen G: Distinguishable prognostic signatures of left- and right-sided colon cancer: A study based on sequencing data. Cell Physiol Biochem 48(2): 475-490, 2018. PMID: 30016783. DOI: $10.1159 / 000491778$

28 Dylag-Trojanowska K, Rogala J, Pach R, Siedlar M, Baran J, Sierzega M, Zybaczynska J, Lenart M, Rutkowska-Zapala M and Szczepanik AM: T regulatory CD4(+)CD25(+)FOXP3(+) lymphocytes in the peripheral blood of left-sided colorectal cancer patients. Medicina (Kaunas) 55(6): 307, 2019. PMID: 31242584. DOI: $10.3390 /$ medicina55060307

29 Atabani SF, Thio CL, Divanovic S, Trompette A, Belkaid Y, Thomas DL and Karp CL: Association of CTLA4 polymorphism with regulatory $\mathrm{T}$ cell frequency. Eur J Immunol 35(7): $2157-$ 2162, 2005. PMID: 15940668. DOI: 10.1002/eji.200526168

30 Zhang X, Kelaria S, Kerstetter J and Wang J: The functional and prognostic implications of regulatory $\mathrm{T}$ cells in colorectal carcinoma. J Gastrointest Oncol 6(3): 307-313, 2015. PMID: 26029458. DOI: $10.3978 /$ j.issn.2078-6891.2015.017

31 Liu Z, Huang Q, Liu G, Dang L, Chu D, Tao K and Wang W: Presence of FOXP3(+)Treg cells is correlated with colorectal cancer progression. Int J Clin Exp Med 7(7): 1781-1785, 2014. PMID: 25126180

32 Pandurangan AK, Divya T, Kumar K, Dineshbabu V, Velavan B and Sudhandiran G: Colorectal carcinogenesis: Insights into the cell death and signal transduction pathways: A review. World J Gastrointest Oncol 10(9): 244-259, 2018. PMID: 30254720. DOI: $10.4251 /$ wjgo.v10.i9.244

33 Nishihara R, Glass K, Mima K, Hamada T, Nowak JA, Qian ZR, Kraft P, Giovannucci EL, Fuchs CS, Chan AT, Quackenbush J, Ogino S and Onnela JP: Biomarker correlation network in colorectal carcinoma by tumor anatomic location. BMC Bioinformatics 18(1): 304, 2017. PMID: 28623901. DOI: 10.1186/s12859-017-1718-5

34 Kalantzis I, Nonni A, Pavlakis K, Delicha EM, Miltiadou K, Kosmas C, Ziras N, Gkoumas $\mathrm{K}$ and Gakiopoulou H: Clinicopathological differences and correlations between right and left colon cancer. World J Clin Cases 8(8): 1424-1443, 2020. PMID: 32368535. DOI: 10.12998/wjcc.v8.i8.1424

35 Shen H, Yang J, Huang Q, Jiang MJ, Tan YN, Fu JF, Zhu LZ, Fang XF and Yuan Y: Different treatment strategies and 
molecular features between right-sided and left-sided colon cancers. World J Gastroenterol 21(21): 6470-6478, 2015. PMID: 26074686. DOI: $10.3748 /$ wjg.v21.i21.6470

36 Baran B, Mert Ozupek N, Yerli Tetik N, Acar E, Bekcioglu O and Baskin Y: Difference between left-sided and right-sided colorectal cancer: A focused review of literature. Gastroenterology Res 11(4): 264-273, 2018. PMID: 30116425. DOI: $10.14740 /$ gr $1062 \mathrm{w}$

37 Torres-Carrillo N, Ontiveros-Mercado H, Torres-Carrillo NM, Parra-Rojas I, Rangel-Villalobos H, Ramírez-Dueñas MG,
Gutiérrez-Ureña SR, Valle Y and Muñoz-Valle JF: The -319C/ +49G/CT60G haplotype of CTLA-4 gene confers susceptibility to rheumatoid arthritis in mexican population. Cell Biochem Biophys 67(3): 1217-1228, 2013. PMID: 23703660. DOI: 10.1007/s12013-013-9640-6

Received December 18, 2020

Revised January 12, 2021

Accepted January 13, 2021 